\title{
Risk perception, trust, and factors related to a planned new nuclear power plant in Taiwan after the 2011 Fukushima disaster
}

\author{
Jung-Chun $\mathrm{Ho}^{1}$, Shu-Fen Kao ${ }^{2}$, Jung-Der Wang ${ }^{3}$, Chien-Tien $\mathrm{Su}^{1}$, \\ Chiao-Tzu Patricia Lee ${ }^{4}$, Ruey-yu Chen ${ }^{1}$, Hung-Lun Chang ${ }^{1}$, \\ Marco C F Ieong ${ }^{1}$ and Peter Wushou Chang ${ }^{1,5}$ \\ ${ }^{1}$ School of Public Health, College of Public Health and Nutrition, Taipei Medical University, \\ 250 Wuxing Street, Taipei 110, Taiwan \\ 2 Department of Sociology, Fo Guang University, 160 Linwei Road, Jiaosi, Yilan County 26247, \\ Taiwan \\ ${ }^{3}$ Department of Public Health, National Cheng Kung University, 1 University Road, \\ Tainan 701, Taiwan \\ ${ }^{4}$ School of Public Health, Gold Coast Campus, Griffith University QLD 4222, Parklands Drive, \\ Southport, Queensland, Australia \\ E-mail: peter.chang3@gmail.com
}

Received 15 April 2013, in final form 21 June 2013, accepted for publication 26 July 2013

Published 19 September 2013

Online at stacks.iop.org/JRP/33/773

\begin{abstract}
After the Fukushima nuclear disaster in March 2011, an international review of nuclear safety indicated that two of the three nuclear power plants (NPPs) operating in Taiwan were listed as the most dangerous in the world. To understand the perception of NPP risks by the public in Taiwan and their attitudes regarding a planned fourth NPP after the Fukushima nuclear incident in 2011, a study was conducted in August 2011. A sample of 2819 individuals responded to the survey, with $66 \%$ perceiving that Taiwan's safety management of NPPs was inferior to Japan's, while $40 \%$ perceived a higher possibility of nuclear accidents like that in Japan. On average, a 'safe' distance of $94 \mathrm{~km}$ from an NPP was expected. 56\% opposed the planned fourth NPP, with females (adjusted odd ratios (aOR) 2.03; 95\% confidence interval (CI) 1.71-2.41), residence near the planned fourth NPP (aOR/CI 13.90/7.79-24.80), distrust of safety management (aOR/CI 1.98/1.45-2.69) and emergency planning (aOR/CI 1.89/1.49-2.40) as the main determinants. Others included those who expected larger safe distances from an NPP (trend test, $\mathrm{p}<0.001$ ), perceived excess cancer risks of living within $30 \mathrm{~km}$ of an NPP (aOR/CI 2.74/2.02-3.71), and projection of no electric shortage without NPPs (aOR/CI 1.93/1.50-2.49). Given

\footnotetext{
5 Address for correspondence: School of Public Health, College of Public Health and Nutrition, Taipei Medical University, Taiwan; Departments of Occupational Medicine, Taipei Medical University Hospital and Shuang Ho Hospital; c/o 250 Wuxing Street, Taipei 11031, Taiwan.
} 
that Taiwan's large population lives close to the existing NPPs and long-term concerns about the safety of these nuclear plants, the Fukushima incident in Japan likely augmented public risk perceptions on nuclear power in general and on the planned fourth NPP.

(Some figures may appear in colour only in the online journal)

\section{Introduction}

On 11 March 2011, a magnitude 9.0 earthquake occurred off the Sanriku coast of Japan that resulted in multiple tsunamis. The earthquake and tsunamis damaged several nuclear power stations, with the Fukushima Dai-ichi Nuclear Power Plant the worst affected. The damage led Japan to declare a state of nuclear emergency that was ultimately set at level 7 'severe accident' on the International Nuclear Event Scale [1]. A major release of radioactivity to the environment was of critical concern due to potential health effects. The Fukushima Nuclear Accident Independent Investigation Commission concluded in July 2012 that the accident was clearly 'man-made', further directing that organisational and regulatory system failures were the accident's root cause [2]. The World Health Organisation provided public health advice after the accident about protective measures as well as safety of food and drinking water, mental health, travel, tourism and trade [3]. On 28 February 2013, the first health risk assessment from the Fukushima nuclear accident based on a preliminary dose estimation by WHO concluded that the lifetime risk for some cancers may have been elevated above baseline rates in certain age and sex groups in those most exposed. The assessment urged continued monitoring of population health impacts as well as of psychological effects from the nuclear accident [4].

Lessons learned from this disaster may help in the development of effective emergency responses and nuclear safety measures. Yet most of the nuclear industry's past efforts have focused on technology and nuclear emergency management, with evaluations of risk perception, risk communication and information sharing usually considered secondary to technical and engineering priorities. After the Fukushima incident, many governments and nuclear operators started to realise the need to understand public perceptions as well as to improve risk communication and emergency messaging [5-7]. In Slovic's early study, risk perception would effectively influence public decision making on public policy [8]. Risk perception examined the judgement people made when they were asked to characterise and evaluate hazardous activities and technologies such as the decision on the location of a new nuclear power plant. The theory emphasised that those who administered and regulated health and safety programmes would benefit from understanding 'how people think about and respond to risk'. Without such understanding, well-intended policies may be ineffective.

It has now been widely recognised that effective communication is a crucial element during and after a nuclear accident and can shape risk perception towards major events [9, 10]. Therefore, risk perception and risk communication research between the regulators, the operators, the communities and stakeholders are much needed in nuclear safety and emergency management, as civil societies are much more involved in decisions on future major industrial development in many modern societies [9, 10].

\subsection{Risk perception and acceptance of nuclear power plants}

Over the past 30 years, limited research has focused on risk perception associated with actual radiological emergencies. Most of this research investigated the effectiveness of 
communicating nuclear risks, especially emergency preparedness or accidents involving severe radiological events. The gap between the public's perception of risks posed by nuclear operations and those estimated by mechanical and engineering analysis has been a significant problem in many democratic societies [11, 12]. Nuclear disasters in particular have had long-term effects on public perception of risks associated with nuclear energy.

Public attitudes towards nuclear operations are increasingly negative, and these attitudes will affect policies regarding current and planned nuclear power plants. Acceptance of nuclear power in many countries has decreased dramatically since the Three Mile Island accident in the late 1970s [13]. Many countries have faced further opposition to nuclear power plants (NPPs) since the Chernobyl accident in 1986 [14]. Public opposition to new NPPs in both the United States and Europe increased from around $20 \%$ in the mid-1970s to more than $60 \%$ in the early 1980s [15]. Public approval of nuclear power continued to be low throughout the 1990s, due to intense public distrust of governments and increasing environmental concerns such as the issue of radioactive waste disposal [16-18].

Many NPPs that were constructed during the 1970s boom are approaching the end of their functional lifetimes. Public uneasiness about nuclear energy is now, more than ever, a major concern worldwide $[12,19]$.

Before the Fukushima accident in 2011, an opinion poll conducted by the International Atomic Energy Agency showed that public acceptance of building new NPPs had begun to increase in the United States (48\% support in 2003, 62\% in 2007) and Europe. In particular, approval rose from 30\% to 36\% in the United Kingdom between 2003 and 2007, with similar increases in Finland (35\% to 45\% from 2001 to 2004), France (42\% to $47 \%$ from 2002 to 2007), Sweden (39\% to 50\% from 2002 to 2005), Hungary (68\% to $74 \%$ from 2002 to 2007) and Japan (32\% to 40\% from 2001 to 2008) [20]. After the Fukushima accident, many countries held public debates on the safety of nuclear energy and conducted serious reviews of their energy policies, and nuclear plants and their operators worldwide face public distrust and opposition.

Public trust is one of the most important factors influencing public acceptance of nuclear power [21]. Several studies revealed that people who were opposed to nuclear power plants (or had high risk perception towards nuclear power) often associated NPPs with potential nuclear accidents, waste disposal, radioactivity and nuclear safety, negative health consequences for health, negative environmental effects and socio-economic impacts [6, 22-25]. The interaction of the local setting exposed to the nuclear power plant with existing personal knowledge and experience had a significant impact on risk perceptions of local residents towards nuclear power [26]. Therefore, it is critical to investigate risk perceptions and acceptance of nuclear facilities by the local residents in related societies.

\subsection{Renewed concerns in Taiwan}

After the Fukushima disaster, the eminent scientific journal Nature highlighted two of Taiwan's three NPPs as the world's most dangerous [27]. Nuclear energy currently contributes slightly less than $20 \%$ of Taiwan's electricity. Taiwan constructed its first nuclear power plant (NPP1) in the 1970s, and three NPPs currently operate six reactors while a fourth NPP had been planned since the early 1990s ([28], figure 1). Shimen (SM) and Wanli (WL) in northern Taiwan are the sites for NPP1 and NPP2; NPP3 is situated in Hengchun (HC) in southern Taiwan (figure 2). NPP1 and NPP2 are located $22 \mathrm{~km}$ and $28 \mathrm{~km}$, respectively, from the centre of the metropolitan Taipei area with a population of more than six million. The population densities of the areas surrounding these NPPs are much higher than any other cities in the world [27], with 5.5 million people living within a $30 \mathrm{~km}$ radius of NPP1 and 4.7 million within the same radius of NPP2; many people are within this distance of both plants. 


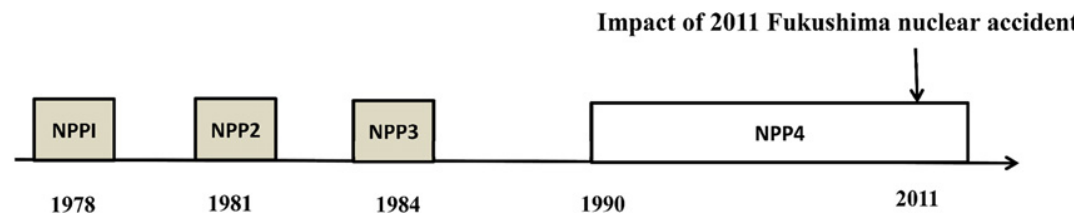

Figure 1. Time series of the development of different nuclear power plants (NPPs) in Taiwan. The construction of the fourth NPP has not been completed.

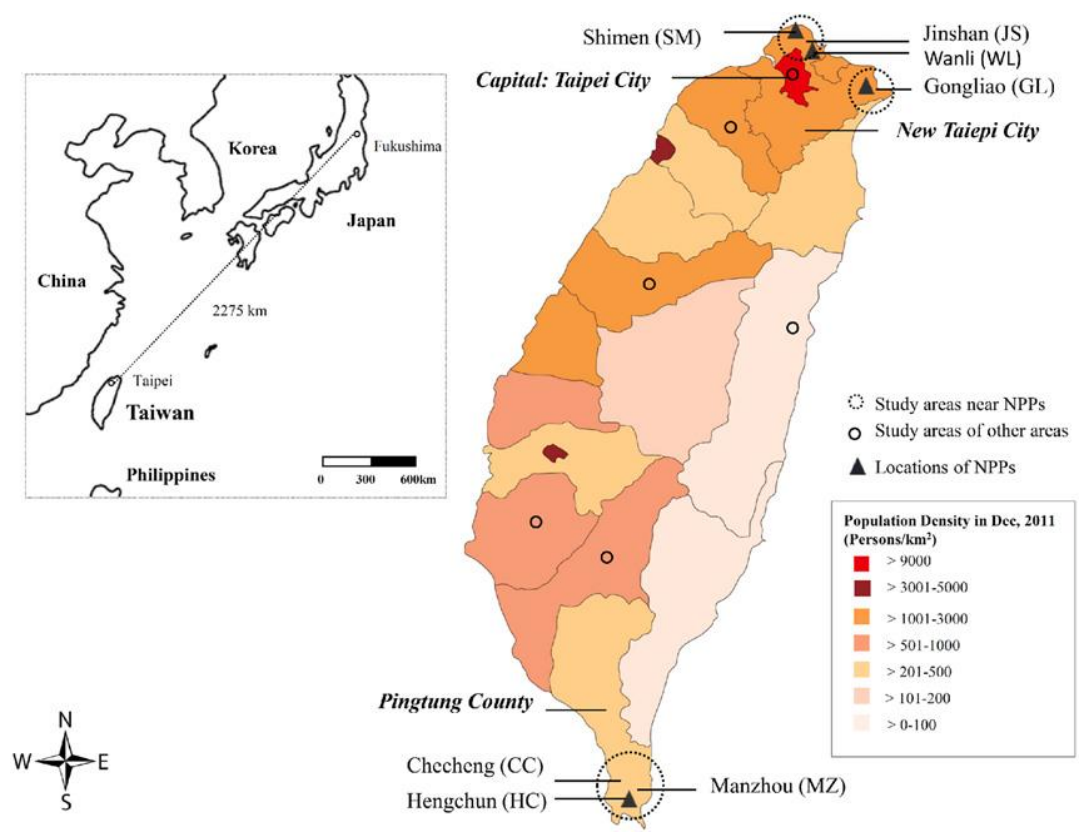

Figure 2. Geographic distribution, distance and population densities of the sample areas near the nuclear power plants in Taiwan.

These power plants have been operated since 1978, 1981 and 1984 (figure 1) by the government-owned Taiwan Electric Power Company (commonly known as Taipower). However, nuclear power plants in Taiwan have been highly controversial since the beginning and a salient example of environmental risk for decades. The fourth NPP in Gongliao (GL) in northeastern Taiwan has been planned since the early 1990s, but is still under construction to date, with strong community resistance. Surveys by the government's Atomic Energy Council showed that more than half of residents near the three NPPs had similar levels of trust in NPP safety (ranging from 58\% to 66\%) between 2006 and 2009, but much less trust in government emergency planning for nuclear accidents $(37 \%-46 \%$ in the same period) [29]. Another recent study showed that people who live near NPP2 regarded it as an extremely high-risk facility, opposed nuclear power and rejected compensation offered by Taipower for its continuous operation. It further indicated that public risk perception hinges on trust, psychological and socio-economic factors, and proximity to the plant [30].

The Fukushima disaster with its catastrophic development, inadequacies in safety management and emergency responses led to further safety concerns in many East Asian countries [31]. Given Taiwan's geopolitical position as a close neighbour to Japan and its 


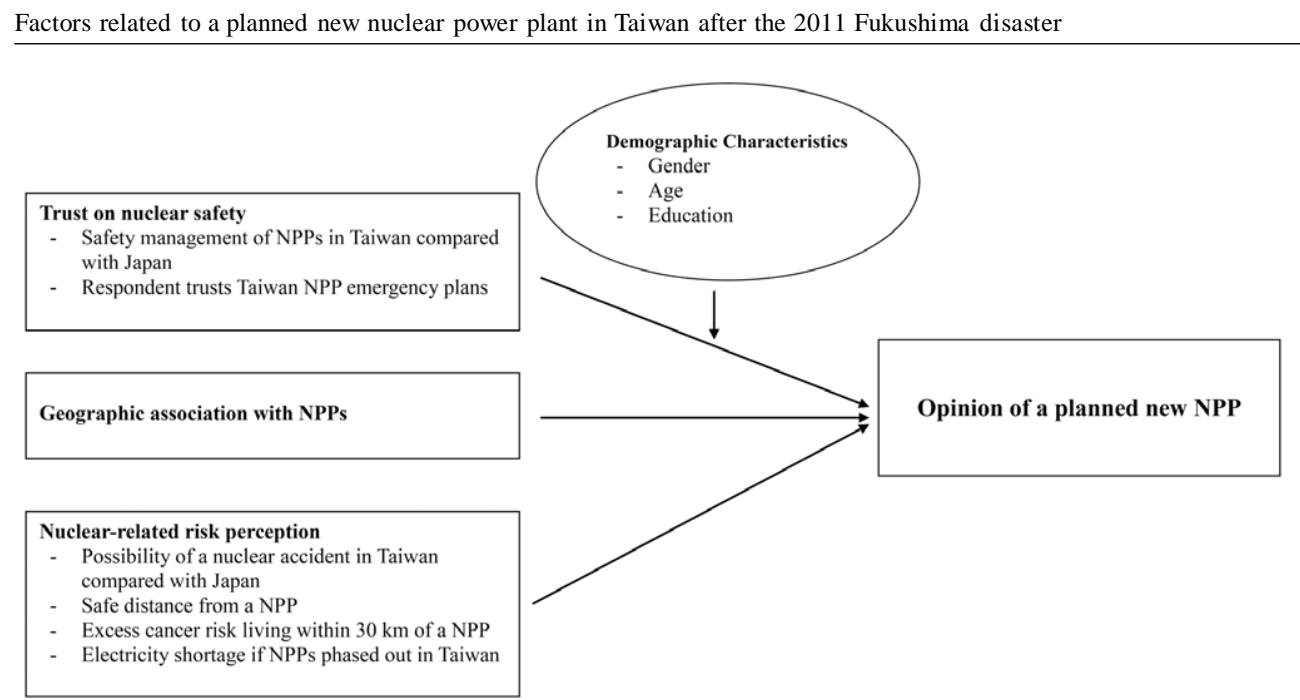

Figure 3. Research hypothesis and analysis framework.

high energy demands, as well as it being one of the most densely populated countries, it was of interest to know how risk perception regarding nuclear energy shifted in Taiwan after the Fukushima nuclear accident. As Taiwan shares many geographic, historical, cultural, political and economic commonalities with Japan, but with different socio-economic development from China and Korea in northeast Asia, this study hypothesised that the Fukushima accident would impact significantly on public trust and public concerns on nuclear safety, ultimately shifting attitudes towards much higher alert and concerns but less trust in nuclear energy (figure 3).

Therefore, the purpose of this study was to investigate changes in public perception towards nuclear risks after the Fukushima incident, and specifically on the acceptance of the planned fourth NPP which has been under construction for more than 20 years. Moreover, this study tried to analyse the association of acceptance of the planned NPP with various determinants, including demographic characteristics (age, gender and education), geographic linkage with the NPP, social trust on nuclear safety (trust of nuclear safety management and related emergency plans) and nuclear-related risk perceptions (perceived possibility of a nuclear accident in Taiwan compared with Japan, perceived safe distance from an NPP, perceived excess cancer risk of living within $30 \mathrm{~km}$ of an NPP and perceived possible electricity shortage if NPPs were phased out in Taiwan) (figure 3).

\section{Methods}

\subsection{Study participants}

A cross-sectional study was conducted from August 2011 for six months. Surveys were performed among community residents in three townships within $5 \mathrm{~km}$ of NPP1 and NPP2 in northern Taiwan (Shimen, Wanli and Jinshan), three townships within $15 \mathrm{~km}$ of NPP3 in southern Taiwan (Hengchun, Manzhou and Checheng) and in the township of Gongliao, within $2 \mathrm{~km}$ of the planned new fourth NPP on Taiwan's northeastern coast (figure 2). Community residents and students in other regions more than $30 \mathrm{~km}$ away from the NPPs were also included in the survey. 


\subsection{Questionnaire interview}

The study was approved by the Institutional Ethics Committee of Taipei Medical University in Taiwan (IRB No: TMU-JIRB-201109002). The collection of questionnaires was undertaken by the participants according to standard guidelines, including face-to-face interview, by research assistants who had received eight hours of specialised training. The questionnaire included social demographic characteristics, social trust on nuclear safety, several specific nuclear-related risk perceptions and opinion on operation of the planned fourth NPP in Taiwan. Thirty volunteers joined the pretest. Several experts including community representatives and opinion leaders who were familiar with the issue were invited to validate the questionnaire's contents and Cronbach's alpha was used to determine the internal consistency of a problem set on nuclear risk perception $(\alpha=0.818,95 \% \mathrm{CI}=0.45-0.49, \mathrm{p}<0.001)$. Interviewees were provided with an explanatory consent form and almost of them answered the questionnaires independently, while a few seniors and handicapped residents were assisted in answering.

In order to compare the responses of different communities, we decided to study all the townships hosting the three existing nuclear power plants, as well as the Gonglian (GL) township which hosts the fourth NPP which is under construction. Out of 346 communities which were beyond $30 \mathrm{~km}$ away from the above area in Taiwan, 17 communities and townships were randomly selected for the study as 'other regions'. With the townships decided, the questionnaires were administered and collected according to the proportion of the total populations of specific townships. To make collection of effective samples from these townships feasibile, interviewers would conduct the surveys during regular daytime hours and mostly on weekdays in each community simultaneously. Interviewers' work stations were set up in several public business locations such as convenience stores, bus stations, main business streets, shopping centres, local administration centres, schools, hospitals and health centres, and local residents who walked into these stations were invited to respond to the questionnaires. Some of the questionnaires were responded to by college students distributed in a dozen townships in the regular classes. More than 3100 persons were invited to take the survey during the study period, with a response rate of $91 \%$. Around half of the respondents were from the local townships hosting the NPPs and the GL township, while the 'other regions' accounted for half of respondents, including local residents, office workers and college students.

\subsection{Dependent and independent variables}

Opinion on the planned fourth NPP was the dependent variable, with respondents asked to respond 'yes' or 'no' to 'Do you approve of the operation of a planned fourth nuclear power plant in Taiwan?' (table 1).

The independent variables included socio-demographic characteristics like gender, age and education level, trust in nuclear safety, as well as specific nuclear-related risk perception. More specifically, the evaluation of trust in nuclear safety included 'safety management of NPPs in Taiwan as compared with those in Japan' and 'trust in emergency plan'. Specific nuclear-related risk perception included 'perceived possibility of a nuclear accident in Taiwan compared with such risk in Japan', 'perceived safe distance from an NPP', 'perceived excess cancer risk from living within $30 \mathrm{~km}$ of an NPP' and 'perceived possibility of electricity shortages if NPPs were phased out in Taiwan (table 1)'.

A five-point Likert scale was used to measure variables in 'trust in nuclear safety' and 'specific nuclear-related perceptions', except for perceived safe distance. Safety management and emergency planning were designated as indicators of trust in nuclear power. For example, respondents were asked 'How do you think the general safety management of nuclear power in Taiwan compares with that in Japan?' with ordinal scales of 'much worse', 'worse', 
Table 1. Respondents' demographic characteristics and perception of nuclear risks. (Abbreviations: NPP, nuclear power plant; km, kilometre; JS, Jinshan; SM, Shimen; WL, Wanli; HC, Hengchun; MZ, Manzhou; CC, Checheng; GL, Gongliao.)

\begin{tabular}{|c|c|c|c|c|c|}
\hline \multirow[b]{2}{*}{ Variable } & \multirow[b]{2}{*}{ Total N (\%) } & \multicolumn{4}{|c|}{$\begin{array}{l}\text { Study townships (geographical association with NPPs), } \\
\mathrm{N}(\%)\end{array}$} \\
\hline & & SM, WL, JS & $\mathrm{HC}, \mathrm{MZ}, \mathrm{CC}$ & GL & Other regions \\
\hline Number of subjects & $2819(100)$ & $481(17)$ & $561(20)$ & $274(10)$ & $1503(53)$ \\
\hline \multicolumn{6}{|l|}{ 1. Social demographic characteristics } \\
\hline Gender (Female) & $1477(52)$ & $272(57)$ & $350(62)$ & $91(33)$ & $764(51)$ \\
\hline \multicolumn{6}{|l|}{ Age } \\
\hline Mean (SD) & $34(16)$ & $35(17)$ & $37(12)$ & $53(17)$ & $29(13)$ \\
\hline$\leq 25$ & $1092(39)$ & $163(34)$ & $70(13)$ & $10(4)$ & $849(57)$ \\
\hline $26-50$ & $1276(45)$ & $230(48)$ & $411(73)$ & $105(38)$ & $530(35)$ \\
\hline$>50$ & $451(16)$ & $88(18)$ & $80(14)$ & $159(58)$ & $124(8)$ \\
\hline \multicolumn{6}{|l|}{ Education } \\
\hline Senior high school or lower & $846(30)$ & $255(53)$ & $174(31)$ & $208(76)$ & $210(14)$ \\
\hline College or university (including current students) & $1973(70)$ & $226(47)$ & $387(69)$ & $66(24)$ & $1293(86)$ \\
\hline \multicolumn{6}{|c|}{ 2. Social trust on nuclear safety } \\
\hline \multicolumn{6}{|c|}{ Safety management of NPPs in Taiwan compared with Japan } \\
\hline Mean (SD) & $4.0(1.0)$ & $3.9(1.0)$ & $4.0(1.0)$ & $4.1(1.0)$ & $4.0(1.0)$ \\
\hline Much worse/worse & $1579(66)$ & $118(55)$ & $307(56)$ & $254(94)$ & $900(66)$ \\
\hline Similar & $592(25)$ & $61(29)$ & $167(31)$ & $15(6)$ & $349(26)$ \\
\hline Better/much better & $223(9)$ & $34(16)$ & $73(13)$ & $1(0)$ & $115(8)$ \\
\hline \multicolumn{6}{|l|}{ Respondent trusts Taiwan NPP emergency plans } \\
\hline Mean (SD) & $3.8(1.0)$ & $3.6(1.0)$ & $3.7(1.0)$ & $3.8(1.0)$ & $3.8(1.0)$ \\
\hline No & $2440(83)$ & $417(84)$ & 455 (79) & $231(80)$ & $1231(83)$ \\
\hline Yes & $379(17)$ & $64(16)$ & $106(21)$ & $43(20)$ & $272(17)$ \\
\hline \multicolumn{6}{|c|}{ 3. Specific nuclear-related risk perceptions } \\
\hline \multicolumn{6}{|c|}{ Perceived possibility of a nuclear accident in Taiwan compared with Japan } \\
\hline Mean (SD) & $3.5(1.0)$ & $3.5(1.0)$ & $3.2(1.0)$ & $3.5(1.0)$ & $3.5(1.0)$ \\
\hline Much higher/higher & $1124(40)$ & $182(38)$ & $203(36)$ & $188(69)$ & $551(37)$ \\
\hline Similar & $1115(40)$ & $166(34)$ & $240(43)$ & $70(25)$ & $639(42)$ \\
\hline Lower/much lower & $580(20)$ & $133(28)$ & $118(21)$ & $16(6)$ & $313(21)$ \\
\hline
\end{tabular}




\begin{tabular}{|c|c|c|c|c|c|}
\hline \multirow[b]{2}{*}{ Variable } & \multirow[b]{2}{*}{ Total N (\%) } & \multicolumn{4}{|c|}{$\begin{array}{l}\text { Study townships (geographical association with NPPs), } \\
\mathrm{N}(\%)\end{array}$} \\
\hline & & SM, WL, JS & $\mathrm{HC}, \mathrm{MZ}, \mathrm{CC}$ & GL & Other regions \\
\hline \multicolumn{6}{|l|}{ Perceived safe distance from an NPP $(\mathrm{km})$} \\
\hline Mean (SD) & $94(88)$ & $100(98)$ & $95(89)$ & $94(83)$ & $92(85)$ \\
\hline$>80$ & $1344(48)$ & $248(51)$ & $294(52)$ & $91(33)$ & $711(47)$ \\
\hline $31-80$ & $827(29)$ & $123(26)$ & $131(24)$ & $132(48)$ & $441(30)$ \\
\hline$\leq 30$ & $648(23)$ & $110(23)$ & $136(24)$ & $51(19)$ & $351(23)$ \\
\hline \multicolumn{6}{|c|}{ Perceived excess cancer risk of living within $30 \mathrm{~km}$ of an NPP } \\
\hline Mean (SD) & $4.3(0.8)$ & $4.1(0.9)$ & $4.1(1.0)$ & $4.8(0.5)$ & $4.3(0.8)$ \\
\hline Yes & $2494(90)$ & $399(85)$ & $459(85)$ & $264(97)$ & $1372(92)$ \\
\hline No & $276(10)$ & $69(15)$ & $84(15)$ & $7(3)$ & $116(8)$ \\
\hline \multicolumn{6}{|c|}{ Perceived possible electricity shortage if NPPs phased out in Taiwan } \\
\hline Mean (SD) & $4.3(0.7)$ & $4.1(0.9)$ & $4.3(0.8)$ & $4.3(0.7)$ & $4.3(0.7)$ \\
\hline No & $1620(54)$ & $226(40)$ & $251(39)$ & $234(84)$ & $909(59)$ \\
\hline Yes & $1199(46)$ & $255(60)$ & $310(61)$ & $40(16)$ & $594(41)$ \\
\hline Opposition to planned fourth NPP in Taiwan & $1578(56)$ & $212(44)$ & $281(50)$ & $258(94)$ & $827(55)$ \\
\hline
\end{tabular}


'similar', 'better' and 'much better'. Another question asked 'What should be the proportion of renewable energy in the country's total electricity supply?' with options of $<10 \%, 10-19 \%$, $20-39 \%, 40-59 \%, 60-79 \%$ and $80-100 \%$. An open-ended question asked respondents what they perceived as 'the safe distance to live from a nuclear power plant'. The answer was noted as $300 \mathrm{~km}$ when respondents cited distances of more than $300 \mathrm{~km}$, as Taiwan is just over $300 \mathrm{~km}$ at its longest distance from north to south.

\subsection{Data analysis}

As the dependent variable (respondent's approval of the fourth NPP) was dichotomous, a logistic regression model was performed to identify the significant determinants which contribute to public opinion towards this NPP, where $\mathrm{p}<0.05$ was considered significant. Because the data for these independent variables, such as distance and several items on nuclear risk perception, did not have normal distributions, they were transformed into categorical variables in the following data analysis. In order to compensate the decrease in statistical power of analysis, those answers with less popular response rates $(<10 \%)$ were combined in the same groups for further analysis. We conducted univariate logistic regression for each variable and then combined significantly associated variables into the multivariate logistic regression model. The predictive models verified the hypothesis and identified associations between opinions on the fourth NPP and other determinant variables. Odd ratios (OR) and 95\% confidence intervals (95\% CI) were also considered, and the data were analysed using SPSS for Windows version 19.0 (SPSS Inc., Chicago, IL, USA).

\section{Results}

\subsection{Demographic characteristics of respondents}

A total of 2819 respondents who completed the questionnaires were included in the data analysis. These included 481 residents in Shimen, Wanli and Jinshan in the north; 561 residents in Hengchun, Manzhou and Checheng in the south; 274 residents in Gongliao township; and 1503 respondents in other townships (table 1). There were 1342 males (48\%) and 1477 females $(52 \%)$; their mean age was 34 years old $( \pm 16) .1973$ respondents $(70 \%)$ were receiving or had completed university education, while the others received senior high school education or lower.

\subsection{Risk perception regarding nuclear power plants}

Geographically, Shimen, Jinshan and Wanli are within $5 \mathrm{~km}$ of the currently operating NPP1 and NPP2 (figure 2). The distance between these three areas and Gongliao, site of the planned fourth NPP, was more than $30 \mathrm{~km}$. Since the fourth NPP has not reached commercial operation, the data from Shimen, Jinshan and Wanli were pooled in a group, while those from Gongliao were treated as a separate group.

The descriptive data (mean and standard deviation) were listed in table 1. However, the data for these items of nuclear risk perception were not shown with normal distributions, they were then transformed into categorical variables in the following data analysis. $66 \%$ of all respondents perceived the safety management of nuclear power in Taiwan as inferior to that in Japan, 25\% perceived it as equal and 9\% perceived it as better. Specifically, 100\% in Gongliao and $92 \%$ of respondents in other regions that are not near NPPs perceived nuclear safety in Taiwan as either inferior to or no different from that in Japan. 
Only $17 \%$ of all respondents expressed trust in Taiwan's NPP emergency planning. Forty per cent perceived the possibility of a nuclear accident in Taiwan to be higher than that in Japan, with an equal number saying the possibility was the same as in Japan.

There were large variations in the perceived safe distance to live from a nuclear power plant (table 1). More than $80 \mathrm{~km}$ was the answer of $48 \%$ of respondents, while $29 \%$ specified $31-80 \mathrm{~km}$, and $23 \%$ less than $30 \mathrm{~km}$. The average perceived safe distance from a nuclear power plant was $94 \mathrm{~km}( \pm 88 \mathrm{~km})$. Geographic differences in these responses were minimal; at 100 $( \pm 98), 95( \pm 89), 94( \pm 83)$ and $92( \pm 85) \mathrm{km}$ these lacked statistically significant differences between areas (one-way ANOVA test; $\mathrm{p}>0.05$ ). Similarly, $90 \%$ of all respondents perceived excess cancer risk from living within $30 \mathrm{~km}$ of an NPP, while 97\% of those in GL expressed such a concern. When asked about electricity shortages if Taiwan's NPPs are phased out, $46 \%$ expressed concern, and on this question significant differences existed between those residing close to the existing NPPs (60-61\%), those in other regions (41\%) and those in Gongliao (16\%).

\subsection{Perceptions regarding the proposed nuclear plant}

Fifty-six per cent of all respondents did not approve of the planned fourth NPP, while 44\% answered otherwise (table 1). Specifically, opposition was voiced by $94 \%$ of respondents in Gongliao, $55 \%$ in the areas that were not close to NPPs, 50\% in Hengchun, Manzhou and Checheng townships, and $44 \%$ in Shimen, Wanli and Jinshan.

We further analysed the responses of respondents $(n=1241)$ who were more positive about the fourth NPP (table 2): $60 \%$ of these perceived potential electricity shortages if the NPPs were phased out. However, $84 \%$ of them perceived excess cancer risks for those living within $30 \mathrm{~km}$ of an NPP, and $67 \%$ said that renewable energy should provide up to $20 \%$ of the nation's electricity. Their average perceived safe distance from a nuclear power plant was $104 \mathrm{~km}( \pm 90)$. In short, even those who did not oppose the fourth NPP remained concerned about nuclear safety and risks.

\subsection{Determinants of opinion about the planned NPP}

Associations between opposition to the fourth NPP and several determinants were further analysed using simple (table 3) and multiple (table 4) logistic linear regression models (Chi square $=549.046$, Nagelkerke $\mathrm{R}$ square $=24.8 \%, \mathrm{p}<0.001$ ). All independent variables (table 3 ) with $\mathrm{p}$ values $<0.05$ were considered significant and included in the multiple logistic regression model. Significantly more female subjects than male subjects (adjusted OR $=2.03$, 95\% CI $=1.71-2.41$; table 4 ) opposed the fourth NPP. Gongliao respondents also opposed the plant significantly more often (adjusted OR $=13.90,95 \% \mathrm{CI}=7.79-24.80$ ) than those in other regions. Those who did not trust nuclear safety management (adjusted OR $=1.98,95 \%$ $\mathrm{CI}=1.45-2.69$ ) or NPP emergency planning (adjusted $\mathrm{OR}=1.89,95 \% \mathrm{CI}=1.49-2.40$ ) also opposed the new plant, as did those who said that larger distances from an NPP would be more safe (trend test, $\mathrm{p}<0.001$ ). Those who perceived higher-than-normal cancer risks from the fourth NPP (adjusted OR $=2.74,95 \% \mathrm{CI}=2.02-3.71$ ) and those who projected no electricity shortages if NPPs are phased out were also significantly opposed to the fourth NPP (adjusted $\mathrm{OR}=1.93,95 \% \mathrm{CI}=1.50-2.49)$.

\section{Discussion}

In summary, this study analysed public risk perceptions regarding NPPs and their relationships to attitudes towards the planned fourth NPP after the Fukushima nuclear accident. We found 
Table 2. Nuclear-related risk perceptions of respondents who did not oppose the fourth nuclear power plant (\%). (Abbreviations: NPP, nuclear power plant; km, kilometre; JS, Jinshan; SM, Shimen; WL, Wanli; HC, Hengchun; MZ, Manzhou; CC, Checheng; GL, Gongliao.)

\begin{tabular}{|c|c|c|c|c|c|}
\hline & \multirow[b]{2}{*}{ Total $\mathrm{N}(\%)$} & \multicolumn{4}{|c|}{ Study townships (geographical association with NPPs), N (\%) } \\
\hline & & JS, SM, WL & $\mathrm{HC}, \mathrm{MZ}, \mathrm{CC}$ & GL & Other regions \\
\hline Number of subjects & $1241(100)$ & $269(22)$ & $280(23)$ & $16(1)$ & $676(54)$ \\
\hline \multicolumn{6}{|l|}{ Possible electricity shortages if NPPs phased out in Taiwan } \\
\hline No & $496(40)$ & $89(43)$ & $81(29)$ & $5(33)$ & $243(36)$ \\
\hline Yes & $745(60)$ & $180(67)$ & $199(71)$ & $11(67)$ & $433(64)$ \\
\hline \multicolumn{6}{|c|}{ Perceived excess cancer risk for those living within $30 \mathrm{~km}$ of an NPP } \\
\hline Yes & $1042(84)$ & $215(80)$ & $218(78)$ & $13(80)$ & $581(86)$ \\
\hline No & $199(16)$ & $54(20)$ & $62(22)$ & $3(20)$ & $95(14)$ \\
\hline \multicolumn{6}{|c|}{ Preferred proportion of renewable energy in nation's total electricity supply } \\
\hline$<20 \%$ & $410(33)$ & $86(32)$ & $95(34)$ & $4(27)$ & $230(34)$ \\
\hline$\geq 20 \%$ & $831(67)$ & $183(68)$ & $185(66)$ & $12(73)$ & $446(66)$ \\
\hline Perceived safe distance from an NPP $(\mathrm{km}$, mean $\pm 1 \mathrm{SD})$ & $104(90)$ & $107(100)$ & $121(100)$ & $81(78)$ & $98(77)$ \\
\hline
\end{tabular}


Table 3. Analysis of determinants for opposition to the fourth nuclear power plant via simple logistic regression. (Abbreviations: NPP, nuclear power plant; km, kilometre.)

\begin{tabular}{|c|c|c|}
\hline & \multicolumn{2}{|c|}{ Oppose the fourth NPP } \\
\hline & Crude odds ratio $(95 \% \mathrm{CI})$ & $P$ value \\
\hline \multicolumn{3}{|l|}{ 1. Social demographic characteristics } \\
\hline Gender (Female) & $1.69(1.45-1.96)$ & $<0.001^{*}$ \\
\hline \multicolumn{3}{|l|}{ Age $(\%)$} \\
\hline$>50$ & $1.56(1.24-1.96)$ & $<0.001^{*}$ \\
\hline $26-50$ & $0.96(0.82-1.23)$ & 0.619 \\
\hline$\geq 25$ & Ref. & \\
\hline \multicolumn{3}{|l|}{ Education $(\%)$} \\
\hline Senior high school or lower & $1.33(1.12-1.57)$ & $0.001^{*}$ \\
\hline $\begin{array}{l}\text { College or university (including current } \\
\text { students) }\end{array}$ & Ref. & \\
\hline \multicolumn{3}{|l|}{ 2. Geographic linkage with NPPs } \\
\hline JS, SM, WL & $0.73(0.59-0.90)$ & $0.003^{*}$ \\
\hline $\mathrm{HC}, \mathrm{MZ}, \mathrm{CC}$ & $0.85(0.70-1.04)$ & 0.111 \\
\hline GL & $13.18(7.76-22.40)$ & $<0.001^{*}$ \\
\hline Other areas & Ref. & \\
\hline \multicolumn{3}{|l|}{ 3. Trust in nuclear safety plans } \\
\hline \multicolumn{3}{|l|}{$\begin{array}{l}\text { Safety management of NPPs in Taiwan } \\
\text { compared with Japan }(\%)\end{array}$} \\
\hline Much worse/worse & $3.43(2.62-4.48)$ & $<0.001^{*}$ \\
\hline Similar & $1.33(0.99-1.78)$ & 0.057 \\
\hline Better/much better & Ref. & \\
\hline \multicolumn{3}{|l|}{$\begin{array}{l}\text { Respondent trusts Taiwan NPP emergency } \\
\text { plans (\%) }\end{array}$} \\
\hline No & $2.79(2.26-3.45)$ & $<0.001^{*}$ \\
\hline Yes & Ref. & \\
\hline \multicolumn{3}{|l|}{ 4. Specific nuclear-related risk perceptions } \\
\hline \multicolumn{3}{|l|}{ Perceived possibility of a nuclear accident in } \\
\hline \multicolumn{3}{|l|}{ Taiwan compared with Japan (\%) } \\
\hline Much higher/higher & $2.20(1.79-2.70)$ & $<0.001$ \\
\hline Similar & $1.32(1.08-1.62)$ & 0.007 \\
\hline Lower/much lower & Ref. & \\
\hline \multicolumn{3}{|l|}{ Perceived safe distance from an NPP $(\mathrm{km}, \%)$} \\
\hline$>80$ & $2.02(1.64-2.49)$ & $<0.001$ \\
\hline $31-80$ & $2.22(1.83-2.69)$ & $<0.001$ \\
\hline$\leq 30$ & Ref. & \\
\hline \multicolumn{3}{|l|}{$\begin{array}{l}\text { Perceived excess cancer risk for those living } \\
\text { within } 30 \mathrm{~km} \text { of an NPP }(\%)\end{array}$} \\
\hline Yes & $4.05(3.08-5.33)$ & $<0.001$ \\
\hline No & Ref. & \\
\hline \multicolumn{3}{|l|}{ Perceived possible electricity shortages if } \\
\hline \multicolumn{3}{|l|}{ Taiwan NPPs are phased out (\%) } \\
\hline No & $1.72(1.39-2.12)$ & $<0.001^{*}$ \\
\hline Yes & Ref. & \\
\hline
\end{tabular}

that most respondents thought that living near NPPs presented risks and that they perceived higher risks of cancer if living within $30 \mathrm{~km}$ of an NPP. They also strongly distrusted the government's ability to manage nuclear emergencies, regarding Taiwan's risk management as inferior to that of Japan. More than half of these respondents opposed the planned fourth NPP, but even those who approved of this project voiced concerns about the safety risks from the 
Table 4. Analysis of determinants for opposition to the fourth nuclear power plant via multiple logistic regression. (Note: model fit (Sig.): Chi square $=549.046$, Nagelkerke R square $=24.8 \%$ ( $\mathrm{p}<0.001)$. Abbreviations: NPP, nuclear power plant; km, kilometre.)

\begin{tabular}{|c|c|c|}
\hline & \multicolumn{2}{|l|}{ Oppose the fourth NPP } \\
\hline & Adjusted odds ratio (95\% CI) & $P$ value \\
\hline \multicolumn{3}{|l|}{ 1. Social demographic characteristics } \\
\hline Gender (Female) & $2.03(1.71-2.41)$ & $<0.001^{*}$ \\
\hline \multicolumn{3}{|l|}{ Age $(\%)$} \\
\hline$>50$ & $1.27(0.95-1.71)$ & 0.110 \\
\hline $26-50$ & $0.88(0.66-1.16)$ & 0.357 \\
\hline$\leq 25$ & Ref. & \\
\hline \multicolumn{3}{|l|}{ Education $(\%)$} \\
\hline Senior high school or lower & $1.01(0.81-1.25)$ & 0.962 \\
\hline $\begin{array}{l}\text { College or university (including current } \\
\text { students) }\end{array}$ & Ref. & \\
\hline \multicolumn{3}{|l|}{ 2. Geographic linkage with NPPs } \\
\hline JS, SM, WL & $0.86(0.67-1.11)$ & 0.236 \\
\hline $\mathrm{HC}, \mathrm{MZ}, \mathrm{CC}$ & $1.19(0.93-1.52)$ & 0.161 \\
\hline GL & $13.90(7.79-24.80)$ & $<0.001^{*}$ \\
\hline Other areas & Ref. & \\
\hline \multicolumn{3}{|l|}{ 3. Trust in nuclear safety plans } \\
\hline \multicolumn{3}{|l|}{ Perceived safety management of NPPs in } \\
\hline \multicolumn{3}{|l|}{ Taiwan compared with Japan (\%) } \\
\hline Much worse/worse & $1.98(1.45-2.69)$ & $<0.001^{*}$ \\
\hline Similar & $1.10(0.80-1.52)$ & 0.566 \\
\hline Better/much better & Ref. & \\
\hline \multicolumn{3}{|l|}{$\begin{array}{l}\text { Respondent trusts Taiwan NPP emergency } \\
\text { plans }(\%)\end{array}$} \\
\hline No & $1.89(1.49-2.40)$ & $<0.001^{*}$ \\
\hline Yes & Ref. & \\
\hline \multicolumn{3}{|l|}{ 4. Specific nuclear-related risk perceptions } \\
\hline \multicolumn{3}{|l|}{ Perceived possibility of a nuclear accident in } \\
\hline \multicolumn{3}{|l|}{ Taiwan compared with Japan (\%) } \\
\hline Much higher/higher & $1.20(0.94-1.52)$ & 0.139 \\
\hline Similar & $0.90(0.72-1.14)$ & 0.388 \\
\hline Lower/much lower & Ref. & \\
\hline \multicolumn{3}{|l|}{ Perceived safe distance from an NPP $(\mathrm{km}, \%)$} \\
\hline$>80$ & $1.58(1.24-2.00)$ & $<0.001$ \\
\hline $31-80$ & $1.84(1.48-2.28)$ & $<0.001$ \\
\hline$\leq 30$ & Ref. & \\
\hline Trend test & $\mathrm{P}<0.001^{*}$ & \\
\hline \multicolumn{3}{|l|}{$\begin{array}{l}\text { Perceived excess cancer risk for those living } \\
\text { within } 30 \mathrm{~km} \text { of an } \operatorname{NPP}(\%)\end{array}$} \\
\hline Yes & $2.74(2.02-3.71)$ & $<0.001$ \\
\hline No & Ref. & \\
\hline \multicolumn{3}{|l|}{ Perceived possible electricity shortages if } \\
\hline \multicolumn{3}{|l|}{ Taiwan NPPs are phased out $(\%)$} \\
\hline No & $1.93(1.50-2.49)$ & $<0.001^{*}$ \\
\hline Yes & Ref. & \\
\hline
\end{tabular}

fourth plant. Concerns about electric power shortages and possible price increases for electricity might be related to these conflicting attitudes. Gender and other important determinants were strongly associated with public risk perceptions about the planned fourth NPP. These significant 
findings conformed with the hypothesis of the study that in Taiwan, with a large population living close to the existing NPPs and long-term apprehension about the safety of these nuclear plants, a nearby major nuclear event like the Fukushima incident was likely to have shown significant impacts and further augmented public risk perceptions, ultimately shifting general attitudes away from nuclear power.

In this study, females were identified as opposing the planned new fourth NPP more than males. A similar study indicated that females perceived higher levels of nuclear risk and more often made associations with appearance descriptions, negative feelings, and negative environmental effects towards the issue of acceptance of replacing nuclear power plants [22].

On the other hand, Gongliao residents were more extremely opposed (94\%) to the project than respondents from other regions. Surprisingly, these GL respondents also demonstrated the highest distrust in the safety management of NPPs in Taiwan (94\%), and perceived the highest possibility of a nuclear accident $(69 \%)$ and the highest excess cancer risk of living within $30 \mathrm{~km}$ of an NPP (97\%). Since GL did not have an operating nuclear facility in its neighbourhood during the study period, the highest alert towards the fourth NPP by the GL residents could be attributed to the perceived risks characterised by a great deal of uncertainty and involuntary involvement, associated with long-term worry and anxiety [10]. They also strongly expressed their mistrust of the government's nuclear emergency planning as well as of NPP safety management.

During the survey, residents of townships near existing NPPs had noted in personal interviews that their communities have high rates of cancer and poor crop yields. Almost none of them agreed with using land in their area as an NPP site. Local residents usually complained that their concerns and needs were not seriously considered by the government or the Taiwan Electric Power Co., a public governmental corporation. The respondents said the siting of the fourth NPP was deficient in public participation, and was only open to limited interest groups. The lack of dialogue and public deliberations associated with this facility has led respondents to distrust the government and the operator. Local residents said that Taipower provided a few electricity allowances and free electrical appliances such as televisions to some households, yet most people rejected compensation cash and would prefer the government to arrange free health examinations [10]. This study also indicated that nuclear risk perceptions were mainly influenced by trust and other psychological and socio-economic factors, such as the perceived effects of NPPs on the quality of everyday life.

In addition, the study suggested that public participation is an essential part of the decision-making process to successfully gain local support for NPP construction. Local cultures, geography-based affective imagery, individual life experiences, and hazard cognition all shape perceptions of environmental risk. Some communities welcome the employment opportunities and economic benefits that come with NPPs, but people are still reluctant to accept hazardous and otherwise noxious facilities such as nuclear waste repositories. Communities and their residents should be fully informed about hazards and about official plans in the case of disasters [34].

Another survey carried out by our research group in the year 2000 found that $42 \%$ of 385 respondents, including 256 residents in the Shimen, Wanli and Jinshan townships and 129 Taiwan Electric Power Co. employees, opposed the construction of a fourth NPP [35]. Our study, based on data collected a few months after the 2011 Fukushima accident, shows that approval of the fourth NPP increased to $56 \%$ in the same communities. However, the opposition to the new NPP by residents close to these townships decreased from $60 \%$ in 2000 to $44 \%$ in 2011 . We speculate that this result may be due to the township residents living close to the existing NPPs expecting that these facilities would be decommissioned earlier if the fourth NPP becomes operational. Hence only $44 \%$ of respondents oppose the new NPP after 
the Fukushima accident (table 1). Stratified analysis (table 2) shows that $67 \%$ of respondents in SM, WL and JS voiced worries about electricity shortages if nuclear power were phased out in Taiwan. Therefore we speculate that both the benefits of adequate electricity and the perceived risks of nuclear plants influence their opinions about nuclear energy.

As expected, concerns about nuclear power plant accidents led to decreased support for nuclear power in the study, and similar findings have been shown elsewhere [32] . A number of earlier studies, such as the Harris Polls in the United States, showed a sharp diminution of public support for nuclear power immediately after the accident, with a subsequent rebound some months later. However, in Taiwan, public opposition to the new fourth NPP continued to increase from around 56\% in our study and in a similar pool, from 58\% in March 2011 to $74 \%$ in March 2013, reported by public polls [33,34]. This reveals that public concerns remain elevated even two years after the Fukushima nuclear incident.

A recent study in Switzerland indicated that negative perceptions and distrust regarding nuclear power intensified after the Fukushima accident, and people's trust in nuclear power before the Fukushima disaster strongly influenced their levels of trust after the accident [35]. A poll of 993 British adults conducted by Ipsos MORI in June 2011 showed that support for nuclear power had fallen to just $28 \%$, its lowest level since the early 1990s, and while support among men was $42 \%$, it had fallen to just $16 \%$ among women [36]. Support for the construction of replacement NPPs was higher among UK men, with $62 \%$ approving, as opposed to a $39 \%$ approval rate among UK women. Our study's similar results show pronounced female opposition to nuclear power. The Swiss and UK studies also show a significant decrease in public acceptance of NPPs shortly after the Fukushima accident. However, it was observed that while several months later public acceptance increased again slightly in the UK, in the Swiss case it remained at low but not completely unacceptable levels (22\%-24\%). The latter study emphasised that promoting fairness of the outcomes and of the decision-making procedure had increased public acceptance of new energy policies, and indicated that perceived benefits and outcome fairness were important determinants of popular acceptance of the decision to rebuild nuclear power plants [23]. Likewise, in the United States, on behalf of the Civil Society Institute, ORC International interviewed 1032 American adults (518 men and 514 women) in February 2012 [37] and found that only 28\% supported nuclear power a year after the Fukushima incident. More than three out of four respondents $(77 \%)$ said that they were more supportive than a year earlier of 'using clean, renewable energy resources - such as wind and solar-and increased energy efficiency as an alternative to more nuclear power in the United States'. A similar result was observed in our study, which found that most respondents supported additional renewable energy sources to meet Taiwan's electricity needs, and that these should account for at least $20 \%$ of national power supplies and eventually replace nuclear energy.

\section{Study limitations}

There remained several limitations in this study. First, the populations of the townships hosting these three NPPs were relatively older populations, as the young generations and children tend to move to the cities. This may have limitations in generalisation of the study results. Second, this study did not utilise a multiple score such as a five-point Likert scale to measure the opinion on the planned fourth NPP (the dependent variable). A future study would benefit from continuous scales or even extensive and meaningful qualitative interviews. Third, the Fukushima accident was not just a single event but rather a number of events with varying impacts after the initial event, but we conducted the survey from August 2011, that is five months after the initial incident. The results would not be able to reflect precisely the impacts 
of serial events. It is possible that a few days' difference in when the respondents were queried could affect the results. A longitudinal follow-up study might be helpful to identify more precisely the impacts incurred.

\section{Conclusion}

This is one of the first studies to assess the risk perceptions regarding nuclear energy since the Fukushima nuclear disaster in Asia. It reveals that less than half of respondents support a new NPP in Taiwan. It also shows that significant numbers of respondents perceived much higher nuclear risks several months after the Fukushima incident, reflecting a lack of trust in nuclear safety and emergency planning, as well as perceptions of higher health risks and larger 'safe distance' estimates regarding NPPs. Given Taiwan's high population density and the large populations surrounding existing nuclear power plants, these risk perception findings can provide a useful reference worldwide.

\section{Acknowledgments}

The authors would like to thank all respondents who participated in the study. We are also grateful for support from the experts and professionals who helped to collect questionnaires from universities, including $\mathrm{Dr}$ Cheng-fung $\mathrm{Lu}$ of National King Men University, Dr Thung-chiao Tseng of the National Police Academy, Dr Wan-hua Hsieh of Tzu-chi University, Dr Lucetta Tsai of National Taipei University, Professor Kuo-ying Wang of National Central University, Professor Albert Li of National Taipei University of Technology, Professor Chin-fen Chen of National Taipei Normal University and Professor Val Crawford of Taipei Medical University. Thanks are also due to Dr Yuan-chieh Yeh, Ms Chao-ying Wu, Ms Chia-ling Su, Ms Hui-ling Li, Ms Lin-chuan Shaw, Ms Wen-chi Ho, Ms Ya-ping Lee, Ms Yi-yu Chen, Mr Kuo-hua Hsu, Ms Chi-fen Chen, Ms Chia-yu Wang, Ms Ching-chen Shih, Ms Mei-hua Yu, Mr Sheng-fa Chang, Mr Jui-chang Chao, Mr Pai-lin Tien, Mr Po-yu Lin, Mr Shu-hui Wu, Mr Chien-shu Hwang, Mr Hsi-hsiang Hsu, Mr Wen-tung Wu, Mr Ying-chung $\mathrm{Su}, \mathrm{Mr}$ Jiun-wei Li and Ms Kuei-ying Yang. This study received partial funding from a Taipei Medical University faculty grant and from the National Science Council.

\section{References}

[1] IAEA (International Atomic Energy Agency) 2011 Fukushima Nuclear Accident Update Log (updates of 12 April 2011) www.iaea.org/newscenter/news/2011/fukushima120411.html

[2] The official report of the Fukushima Nuclear Accident Independent Investigation Commission (NAIIC), Japan 2012 http://naiic.go.jp/en/

[3] van Deventer E et al 2012 WHO's public health agenda in response to the Fukushima Daiichi nuclear accident J. Radiol. Prot. 32 N119-122

[4] World Health Organization 2013 Health risk assessment from the nuclear accident afetr the 2011 Great East Japan Earthquake Tsunami based on a preliminary dose estimation www.who.int/ionizing radiation/pub _ meet/fukushima_risk_assessment_2013/en/index.html

[5] Becker S M 2011 Risk communication and radiological/nuclear terrorism: a strategic view Health Phys. $101551-8$

[6] Jenkins-Smith H C et al 2011 Reversing nuclear opposition: evolving public acceptance of a permanent nuclear waste disposal facility Risk Anal. 31 629-44

[7] Greenberg M R 2009 NIMBY, CLAMP, and the location of new nuclear-related facilities: US national and 11 site-specific surveys Risk Anal. 29 1242-54

[8] Slovic P 1987 Perception of risk Science 236 280-5

[9] Robertson A G and Pengilley A 2012 Fukushima nuclear incident: the challenges of risk communication Asia Pac. J. Public Health 24 689-96 
[10] Covello V T 2011 Risk communication, radiation, and radiological emergencies: strategies, tools, and techniques Health Phys. 101 511-30

[11] Johnson R H Jr 2001 The role of the radiation safety specialist as witness: risk communication with attorneys, judges, and jurors Health Phys. 81 661-9

[12] Kanda R, Tsuji S and Yonehara H 2012 Perceived risk of nuclear power and other risks during the last 25 years in Japan Health Phys. 102 384-90

[13] Moss T H and Sills D L 1981 The Three Mile Island nuclear accident: lessons and implications Ann. New York Acad. Sci. 365 1-343

[14] Fry F A 1987 The Chernobyl reactor accident: the impact on the United Kingdom Br. J. Radiol. 60 1147-58

[15] Van Der Pligt J, Eiser J R and Spears R 1986 Construction of a nuclear power station in one's locality: attitudes and salience Basic Appl. Soc. Psychol. 7 1-15

[16] Pidgeon N, Hood C, Jones D K, Turner B A and Gibson R 1992 Risk perception Risk Analysis, Perception and Management: Report of a Royal Society Study Group (London: Royal Society)

[17] Poortinga W and Pidgeon N F 2004 Trust, the asymmetry principle, and the role of prior beliefs Risk Anal. 24 1475-86

[18] Garrick B J and Kaplan S 1999 A decision theory perspective on the disposal of high-level radioactive waste Risk Anal. 19 903-13

[19] Costa-Font J, Rudisill C and Mossialos E 2008 Attitudes as an expression of knowledge and 'political anchoring': the case of nuclear power in the United Kingdom Risk Anal. 28 1273-88

[20] OECD N N 2010 Public Attitude to Nuclear Power 2010 available at: www.oecd-nea.org/ndd/reports/2010/ nea6859-public-attitudes.pdf (access April)

[21] Visschers V H and Siegrist M 2013 How a nuclear power plant accident influences acceptance of nuclear power: results of a longitudinal study before and after the Fukushima disaster Risk Anal. 33 333-47

[22] Keller C, Visschers V and Siegrist M 2012 Affective imagery and acceptance of replacing nuclear power plants Risk Anal. 32 464-77

[23] Visschers V H and Siegrist M 2012 Fair play in energy policy decisions: procedural fairness, outcome fairness and acceptance of the decision to rebuild nuclear power plants Energy Policy 46 292-300

[24] Aldrich D P 2012 Post-crisis Japanese nuclear policy: from top-down directives to bottom-up activism Asia Pac. Issues 103 1-12

[25] Parkhill K A et al 2010 From the familiar to the extraordinary: local residents' perceptions of risk when living with nuclear power in the UK Trans. Inst. Br. Geogr. 35 39-58

[26] Hung H-C 2009 The attitude towards flood insurance purchase when respondents' perferences are uncertain: a fuzzy approach J. Risk Res. 12 239-58

[27] Butler D 2011 Nuclear safety: reactors, residents and risk Nature 472 400-1

[28] Liu C C, Chao J H and Lin C C 2003 Tritium release from nuclear power plants in Taiwan Health Phys. 84 361-7

[29] Atomic Energy Council T 2010 The Technology Report of Opinion Poll of Emergency Plan on Nuclear Accidents in 2006-2009 www.aec.gov.tw/www/99/files/index 13 99-3.pdf

[30] Hung H C and Wang T W 2011 Determinants and mapping of collective perceptions of technological risk: the case of the second nuclear power plant in Taiwan Risk Anal. 31 668-83

[31] Fu D W 2011 Introduction of an East Asian STS panel discussion on Japan's 3/11 and Fukushima crisis East Asian Sci., Technol. Soc. 5 377-9

[32] Greenberg M and Truelove H B 2011 Energy choices and risk beliefs: is it just global warming and fear of a nuclear power plant accident? Risk Anal. 31 819-31

[33] Wang C 2013 Almost 70\% back scrapping power plant: poll Taipei Times www.taipeitimes.com/News/front/ archives/2013/03/13/2003556945

[34] Ying-cheng J 2011 Cold comfort for anti-nuclear Taiwanese Asia Times http://atimes.com/atimes/China/ MC29Ad02.html

[35] Visschers V H and Siegrist M 2012 How a nuclear power plant accident influences acceptance of nuclear power: results of a longitudinal study before and after the Fukushima disaster Risk Anal. 33 333-47

[36] World Nuclear News 2012 Fukushima a 'temporary blip' for UK support, 18 January www.world-nuclearnews.org/NP-Fukushima_a_temporary blip for_UK_support-1801124.htm

[37] Hixson L W 2012 Post-Fukushima survey shows less than one-third of Americans supportive of nuclear power Enformable Nuclear News 8 March http://enformable.com/2012/03/post-fukushima-survey-showsless-than-one-third-of-americans-supportive-of-nuclear-power/ 